\title{
Use of Artificial Neural Network for the Prediction of Ammonia Emission Concentration of Granulated Blast Furnace Slag Mortar
}

\author{
Hongseok Jang ${ }^{1}$, Malrey Lee ${ }^{2}$ and Seungyoung $\mathrm{So}^{3 *}$ \\ ${ }^{1}$ Dept. of Architectural Engineering, Chonbuk National University, Republic of Korea, \\ ${ }^{2}$ The research Center for Advanced Image and Information Technology, School of \\ Electronics and information Engineering, Chonbuk National University, \\ Republic of Korea \\ ${ }^{3}$ Research Center of Industrial Technology, Dept. of Architectural Engineering, \\ Chonbuk National University, Republic of Korea \\ ${ }^{1}$ rcit@jbnu.ac.kr, ${ }^{2}$ mrlee@jbnu.ac.kr, ${ }^{3}$ archiso@jbnu.ac.kr

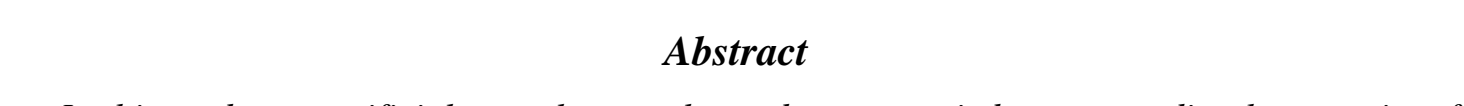

In this study, an artificial neural networks study was carried out to predict the quantity of ammonia gas $\left(\mathrm{NH}_{3}\right)$ of Granulated Blast Furnace Slog (GBFS) cêment mortar. A data set of a laboratory work, in which a total of 4 mortars were produced, was utilized in the Artificial Neural Networks (ANNs) study. The mortar mixture parometers were four different GBFS ratios $(0 \%, 20 \%, 40 \%$ and $60 \%)$. Measurement ammonia of moist cured specimens were measured at 1, 3, 10, 30, 100, 365 days. ANN model is Constructed, trained and tested using these data. The data used in the ANN model are aranged in a format of two input parameters that cover the cement, GBFS andage of samples and, an output parameter which is concentrations of ammonia emission of mortar The results showed that ANN can be an alternative approach for the predicting the ammonia concentration of GBFS mortar using mortar ingredients as input parameters.

Keywords: Neural network; Cementmortar; GBFS; Ammonia

\section{Introduction}

When visiting underground spaces that have poor ventilation or building that are surrounded by cement concrete, we can detect a pungent odor as the unique smell of concrete. This odor is caused by the various gases occurring by the hydration process of cement concrete (or mortar), while the amount and types of gas depend on the composite material. In addition, the gases can significantly influence the health of residents who live in such spaces or workerswho are working in a sealed space surrounded by concrete on a construction site. Among these gases, ammonia gas can be released to indoor-outdoor environment through diffasion in concrete wall and have resulted in the increasing air pollution, and especially well known as a very harmful gas for the human body [1].

Ammonia is a colorless, flammable alkaline gas with a pungent odor and is produced by the decomposition of nitrogenous organic matter [2,3]. The US Department of Health and Human Services has reported on the hazardous properties of ammonia and presented an occupational safety and health guideline for ammonia [4]. According to the Occupational Safety and Health Administration (OSHA), continuous exposure to above 25ppm of ammonia in the air can cause headaches, nausea and even serious burning of the eyes, nose, throat and skin. Exposure to very high levels of ammonia gas can cause serious burns and permanent 
damage to the eyes, lungs and skin [5]. Therefore, OSHA recommends that the level of ammonia in workroom air should be limited to 50ppm for 5 minutes exposure [6].

Recently, the cases of damage of residents or workers on construction sites due to an excessive concentration of indoor ammonia have significantly increased, and reducing the risk caused by ammonia in indoor air becomes a significant issue in Korea [7]. However, only a few investigations on ammonia released from cement concrete have been carried out.

The focus of this paper is to construct an ANN model to predict the concentration of GBFS mortar using mortar ingredients and age. For this purpose, a computer program was developed in MATLAB. Furthermore, the results obtained from the ANN model were compared with the average results of the experiments.

\section{Experiments}

\subsection{Properties of Materials}

2.1.1. Cement: The cement used was Ordinary Portland Cement (OPC) with a specific gravity of $3.16 \mathrm{~g} / \mathrm{cm}^{3}$. Initial and final setting times of the cement were $2 \mathrm{~h}$ and $3 \mathrm{~h} 30 \mathrm{~min}$, respectively. Its blain specific surface area was $3250 \mathrm{~cm} / \mathrm{g}$ and its chemical composition is given in Table 1.

Table 1. Chemical Composition of Materials

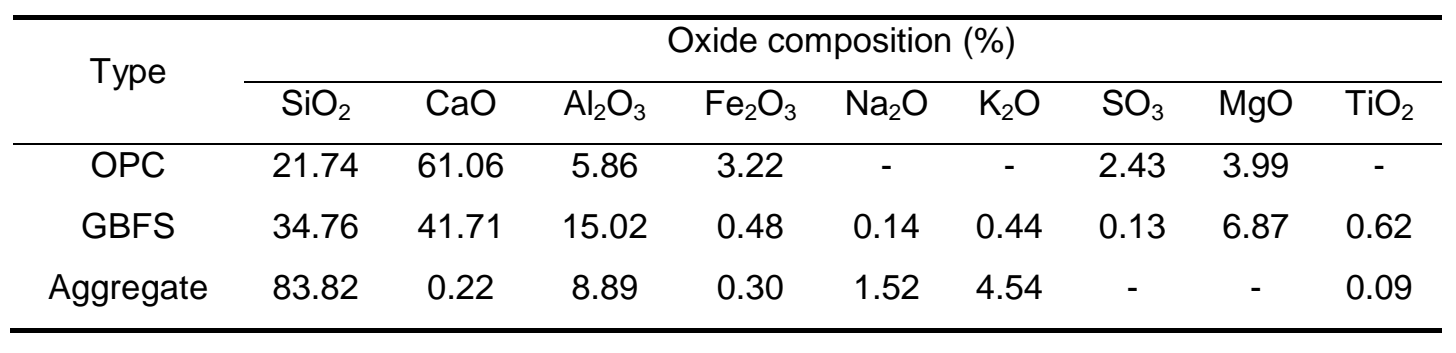

2.1.2. Granulated Blast Furnace Slag: The GBFS used was obtained from a K steel plant in Korea and had a blain specific surface area about $4200 \mathrm{~cm}^{2} / \mathrm{g}$, and specific gravity of $2.91 \mathrm{~g} / \mathrm{cm}^{3}$. Also, according to $\mathrm{KS} 2563$, the GBFS used was classified as a category 3 slag (Table 2).

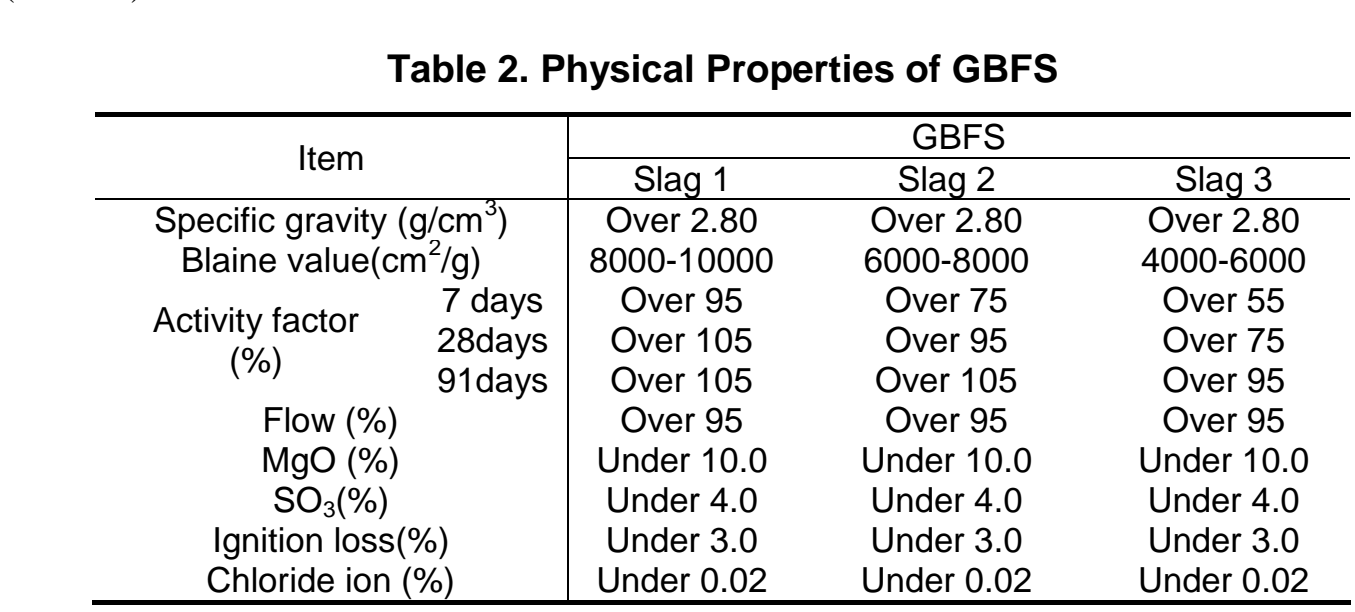


2.1.3. Aggregate: Dry and clean natural, river aggregate was used in mortar mixture. The water absorption value of the sand used was $2 \%$ and its relative density at saturated surface dry condition was $2.65 \mathrm{~g} / \mathrm{cm}^{3}$.

\subsection{Mortar Mixture Proportions}

Four specimens were prepared by mixing different proportions of GBFS and OPC, as shown in Table 3. GBFS was mixed $0 \%, 20 \%, 40 \%$ and $60 \%$ by mass of binder (OPC+GBFS). The mortars were mixed binder and sand in the ratio of one to 2.45 , and water to binder ratio (W/B) was set to 0.50 . All specimens were cast into a mold of dimensions $150 \times 150 \times 50 \mathrm{~mm}$ to measure the concentration of $\mathrm{NH}_{3}$. The size of cement concrete for analyzing the emission of $\mathrm{NH}_{3}$ was $150 \times 150 \times 50 \mathrm{~mm}$ and the mortar has been placed into the environmental chamber, as shown in Figure 1. The environmental chamber was then immediately sealed and cured for 3 hour in a constant temperature and humidity chamber at $20 \pm 2{ }^{\circ} \mathrm{C}$.

\subsection{Test Procedure}

\begin{tabular}{|c|c|c|c|c|}
\hline Type & OPC & GBFS & Aggregate & $\mathrm{W} / \mathrm{B}(\%)$ \\
\hline GBFS-0 & 1000 & - & & \\
\hline GBFS-20 & 800 & 200 & & 50 \\
\hline GBFS-40 & 600 & & & \\
\hline GBFS-60 & 400 & 600 & & \\
\hline
\end{tabular}

The environmental chamber sampling system used in this study was especially designed and consists mainly of a $0.02 \mathrm{~m}^{3}$ stainless steel environmental chamber and mortar holder as shown in Figure 2, and gas sampling system as shown in Figure 3. Sampling of gases was performed by collecting the gases directly in an impinger using a MFC pump for gases released from cement nortar within the hydration stage of each days. Although the load factors of samples generally used in the environmental chamber are $2.0 \mathrm{~m}^{2} / \mathrm{m}^{3}( \pm 10 \%)$ for solid and $0.5 \mathrm{~m}^{2} / \mathrm{m}^{3}( \pm 10 \%)$ for liquid, the load factor of $1.0 \mathrm{~m}^{2} / \mathrm{m}^{3}( \pm 10 \%)$ in this work was used because mortar is in the semisolid state before hardening by the hydration of cement.

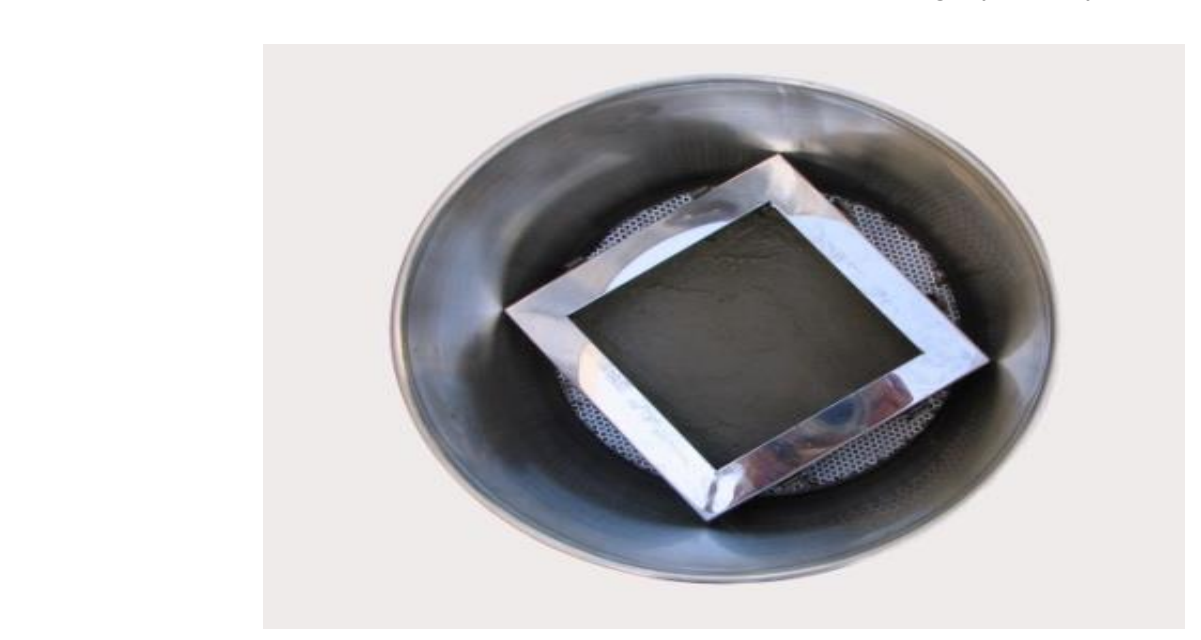

Figure 1. Placing Mortar into the Environmental Chamber 


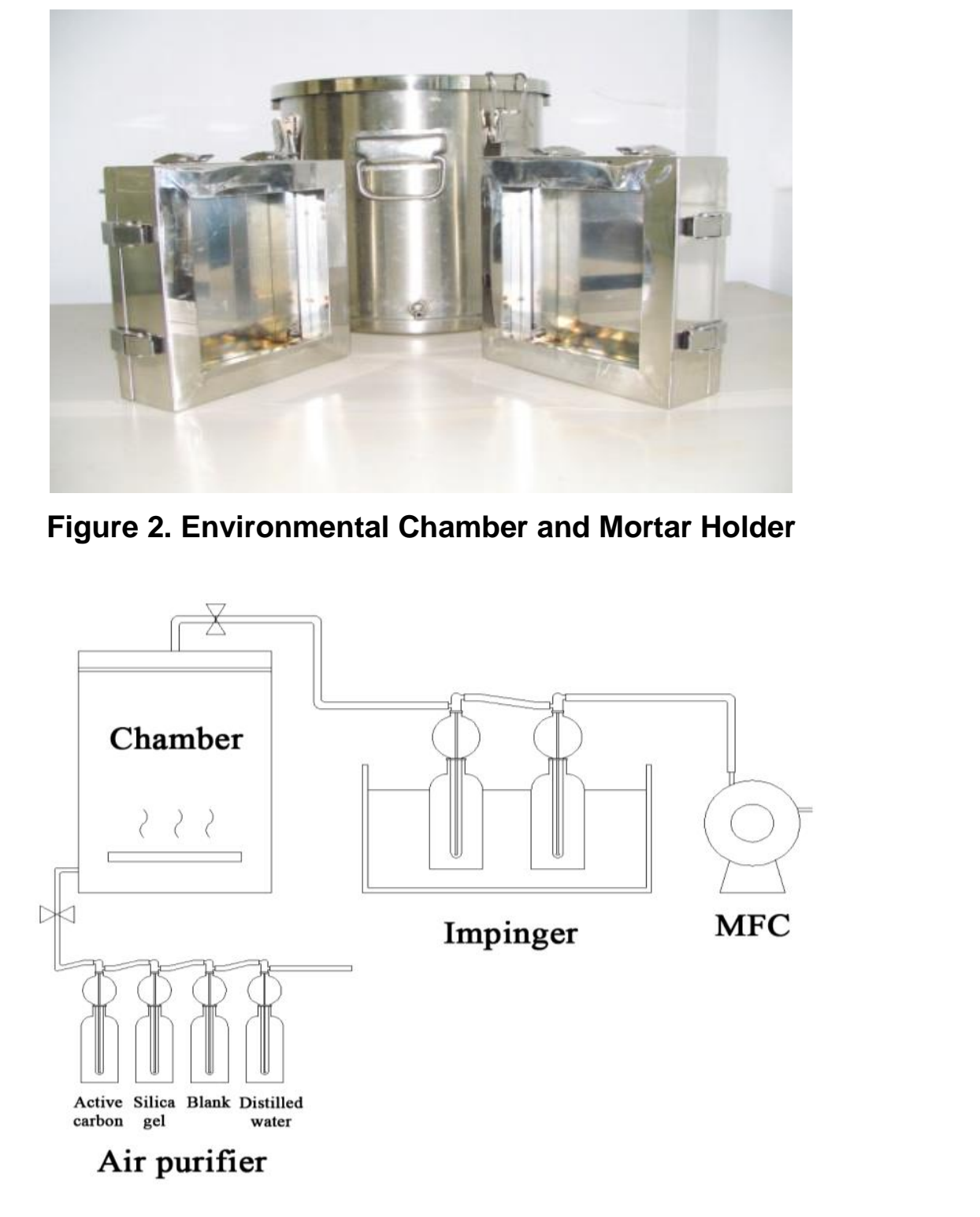

\subsection{Theory ând Calculation}

Figure 3. Gas Sampling System

Ammonia concentration was determined via spectrometric method. The ammonia in gas stream should be first absorbed in boracic acid $\left(\mathrm{H}_{3} \mathrm{BO}_{3}\right)$ solution, in which ammonia reacts w th hypochlorite to form chloramines. Chloramines then react with phenol to form the internediate, named monochloro quinoimine. Finally, this intermediate couples with a second phenolic molecule to form indophenols blue. 


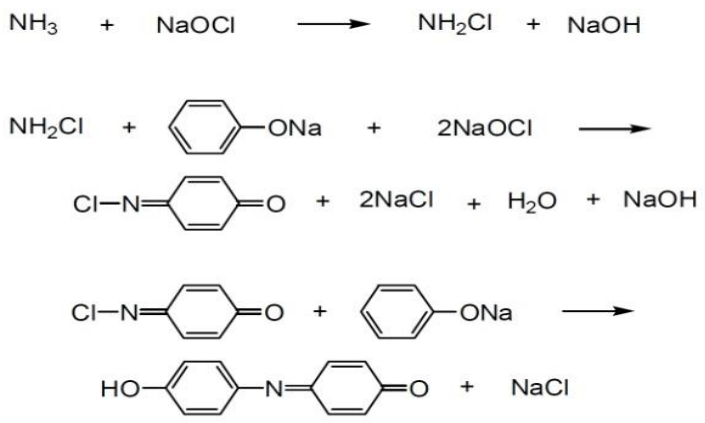

(1)

Indophenol reaction can be described by eq. (1) (3). Ammonia reacts with a hypochlorite $\left(\mathrm{OCl}^{-}\right)$to form a monochloramine (eq.1), which in turn reacts with two phenates fo form an indophenols dye (eq. 2 and eq. 3). Stoichiometry of the overall reaction tells us that the $1 \mathrm{~mol}$ of ammonia reacts with $2 \mathrm{~mol}$ of phenate and $3 \mathrm{~mol}$ of $\mathrm{OCl}^{-}$to form 1 piol ofindophenols. Concentration of ammonia is determined by measuring the absolbance of indophenols at $\lambda=$ $640 \mathrm{~nm}$ with a spectrophotometer.

$\mu \mathrm{g} / \mathrm{m}^{3} \mathrm{NH}_{3}=\mathrm{W} / \mathrm{V}_{\mathrm{o}}$

Where $\mathrm{W}=\mu \mathrm{g} \mathrm{NH}_{3}$ from standard curve

$\mathrm{V}_{\mathrm{o}}=$ Volume of air sample in $\mathrm{m}^{3}$ at $25^{\circ} \mathrm{C}$

$V_{o}=A \times \frac{273}{273+T} \times \frac{P}{760}$

Where $\mathrm{A}=$ MFC volume air

$\mathrm{P}=$ atmospheric pressure at sampling point

$\mathrm{T}=$ temperature, ${ }^{\circ} \mathrm{C}$ at sanpling point

\subsection{Methods}

For the coiormetric determination of ammonia, spectrophotometer (Optizen 2120) was used at 640nm with a ligh patb of $1 \mathrm{~cm}$ unless specified otherwise, analytical grade reagents were obtained from chemical suppliers and used as received. All aqueous solution were made in water purified.

2.5.1. Indophenol Formation: According to the procedure of KSM, 1, 2, 4, 8, 10, 15, $20 \mathrm{~mL}$ of standard anmonium solution (5ppm) was added into each of $50 \mathrm{~mL}$ volumetric flask and $30 \mathrm{~mL}$ of water was added. $10 \mathrm{~mL}$ of sodium phenate, $1 \mathrm{~mL}$ of nitroprusside and $5 \mathrm{~mL}$ of hypochlorte solution were added, and then water was added up to the marked line (final concentrations of each solutions are $0.1,0.2,0.4,0.8,1,1.5,2 \mathrm{ppm}$ ). Mix it gently and leave it at $20 \sim 25^{\circ} \mathrm{C}$ in temperature of solution for $30 \mathrm{~min}$.

2.5.2. Absorbance Sensitivity and Color Stability: Absorbance of indophenol in each experiment was measured and the calibration curve was obtained by plotting absorbance against ammonia concentration. The slope of linear correlation is defined as 'absorbance sensitivity' and the slopes of experiment groups were compared to discuss the quality of ammonia analysis. 

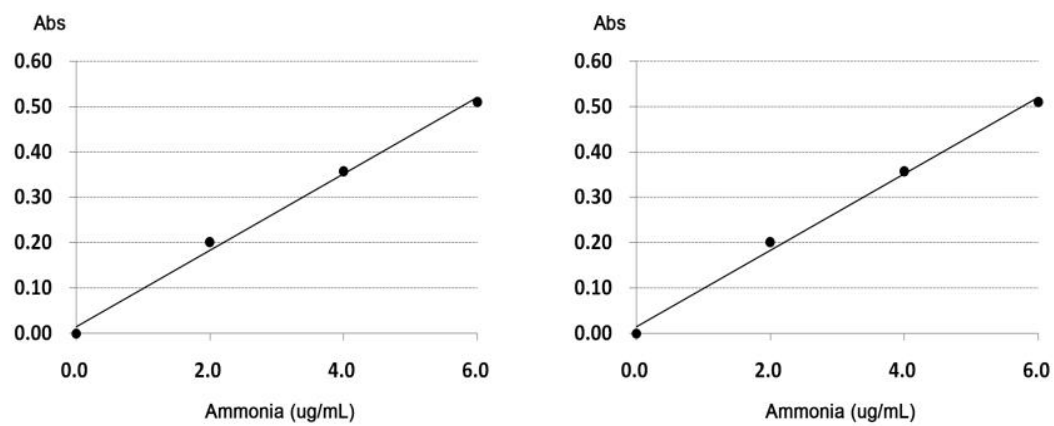

$$
\text { Abs }=0.077 \times \text { Concent. }\left(R^{2}=1\right)
$$

1-day

Abs $=0.080 \times$ Concent. $\left(R^{2}=1\right)$
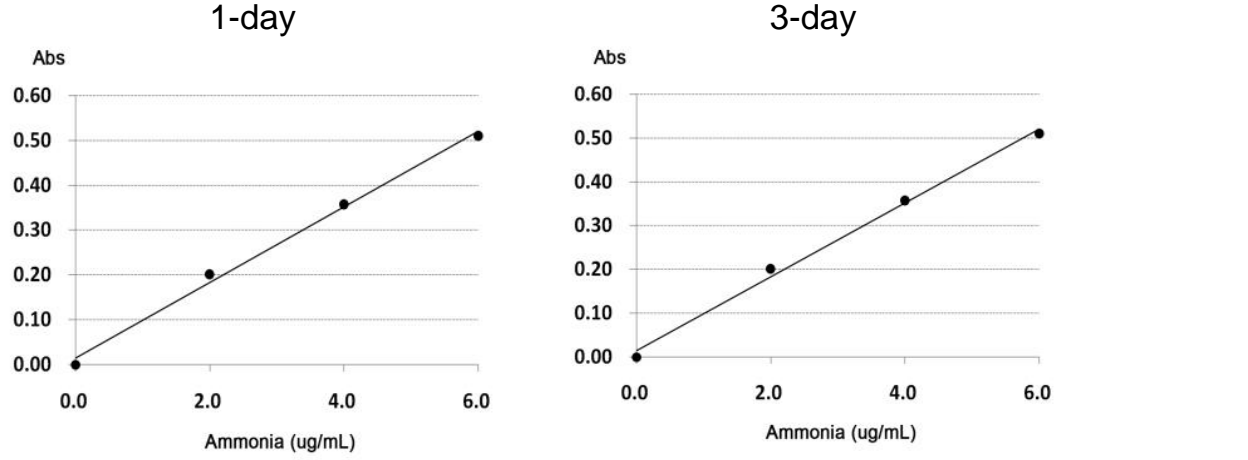

Abs $=0.076 \times$ Concent. $\left(R^{2}=1\right) \bigcirc$ Abs $=0.074 \times$ Concent. $\left(R^{2}=1\right)$

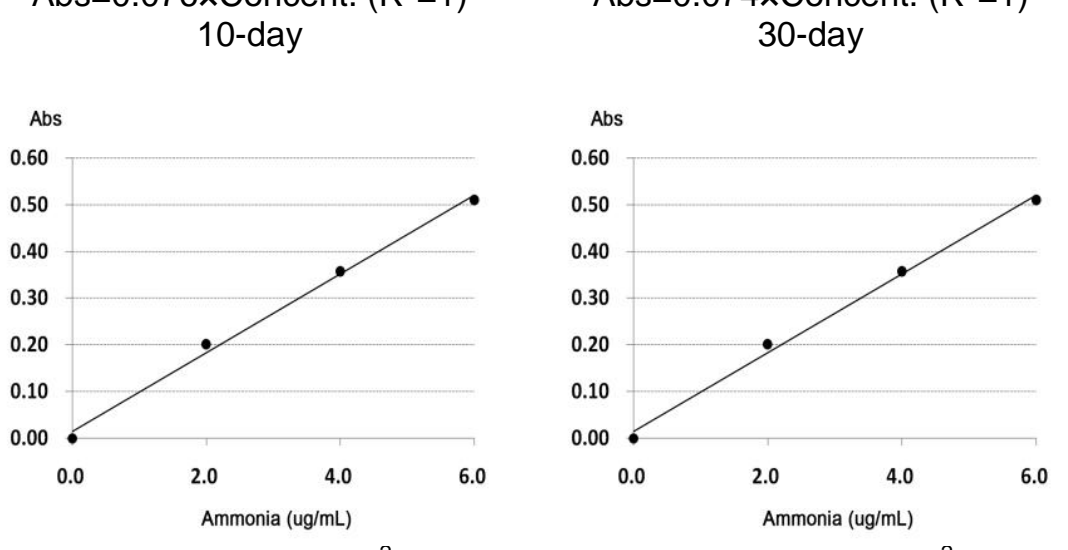

Abs $=0,080$ Concent. $\left(R^{2}=0.99\right)$

100-day

Abs $=0.074 \times$ Concent. $\left(R^{2}=0.99\right)$ 365-day

\section{Figure 4. Calibration Curve by Age}

\section{Results and Discussion}

\subsection{Experimental Results}

Table 4 shows the concentration of ammonia released from cement mortar. Emission of ammonia of mortar containing GBFS mortar is higher than that of control OPC mortar for $20 \%, 40 \%$ and $60 \%$ replacement ration at all days. For example, It can be seen from Table 4 (see 1-day) that the concentration of ammonia of the GBFS-60 is about 1144, which was more than 13.7 times that of the OPC mortar, and increases about 2.2 times for 30-day, 1.7 times for 100-day.

Furthermore, when compared to control OPC mortar, the increase in the GBFS 
replacement ratio increases more the emission of ammonia of mortar having particularly high percentage of GBFS. For instance, in comparison with control OPC mortar, the emission of ammonia at 3 days replacement ratio are increasing 2.5 times, 4.3times, 10.2 times for $20 \%$, $40 \%$ and $60 \%$ GBFS replacement ratios, respectively.

The results obtained in this laboratory research which conducted to the mortars made with GBFS replacement by weight increases the emission of ammonia at early ages when compared to control OPC mortar. This increase observed at the beginning is due to the relatively faster rate of early hydration process. But at later ages GBFS, which is latently hydraulic, undergoes late hydration reactions

Table 4. Ammonia Emission of the Mortar by Age

\begin{tabular}{|c|c|c|c|c|}
\hline & Type & Absorbance (Abs) & Ammonia (ml) & Specimen $\left(u g / m^{3}-h\right)$ \\
\hline \multirow{4}{*}{ 1-day } & OPC Mortar & 0.1417 & 2.70 & \\
\hline & GBFS-20 & 0.2675 & 6.00 & \\
\hline & GBFS-40 & 0.3444 & & 9 \\
\hline & GBFS-60 & 0.7730 & & 1143.9 \\
\hline \multirow{4}{*}{ 3-day } & OPC Mortar & 0.320 & 7.30 & 380.7 \\
\hline & GBFS-20 & 0.669 & & 969.3 \\
\hline & GBFS-40 & & 26.60 & 1629.1 \\
\hline & GBFS-60 & & 61.60 & 3893.1 \\
\hline \multirow{4}{*}{ 10-day } & OPC Mortar & & 3.82 & 402.6 \\
\hline & GBFS-20 & & 11.29 & 1369.4 \\
\hline & & & 20.28 & 2531.5 \\
\hline & & 1.873 & 22.43 & 2810.4 \\
\hline \multirow{4}{*}{ 30-day } & & 0.302 & 3.55 & 367.2 \\
\hline & & 0.505 & 5.93 & 675.6 \\
\hline & & 0.557 & 6.54 & 754.5 \\
\hline & GBFS & 0.588 & 6.90 & 801.6 \\
\hline \multirow{8}{*}{ 365-day } & OPC Mortar & 0.084 & 1.83 & 26.6 \\
\hline & & 0.095 & 2.07 & 42.0 \\
\hline & GBFS-40 & 0.111 & 2.41 & 64.5 \\
\hline & GBFS-60 & 0.098 & 2.13 & 46.2 \\
\hline & OPC Mortar & 0.066 & 0.76 & 7.0 \\
\hline & GBFS-20 & 0.067 & 0.77 & 8.3 \\
\hline & GBFS-40 & 0.067 & 0.77 & 8.3 \\
\hline & GBFS-60 & 0.072 & 0.83 & 16.0 \\
\hline
\end{tabular}




\subsection{Artificial Neural Network Model for Prediction of Experimental Results}

Artificial neural networks (ANNs) are biologically inspired and mimic the human brain. They are consisting of a large number of simple processing elements called as neurons. A schematic diagram for an artificial neuron model is given in Figure 5.

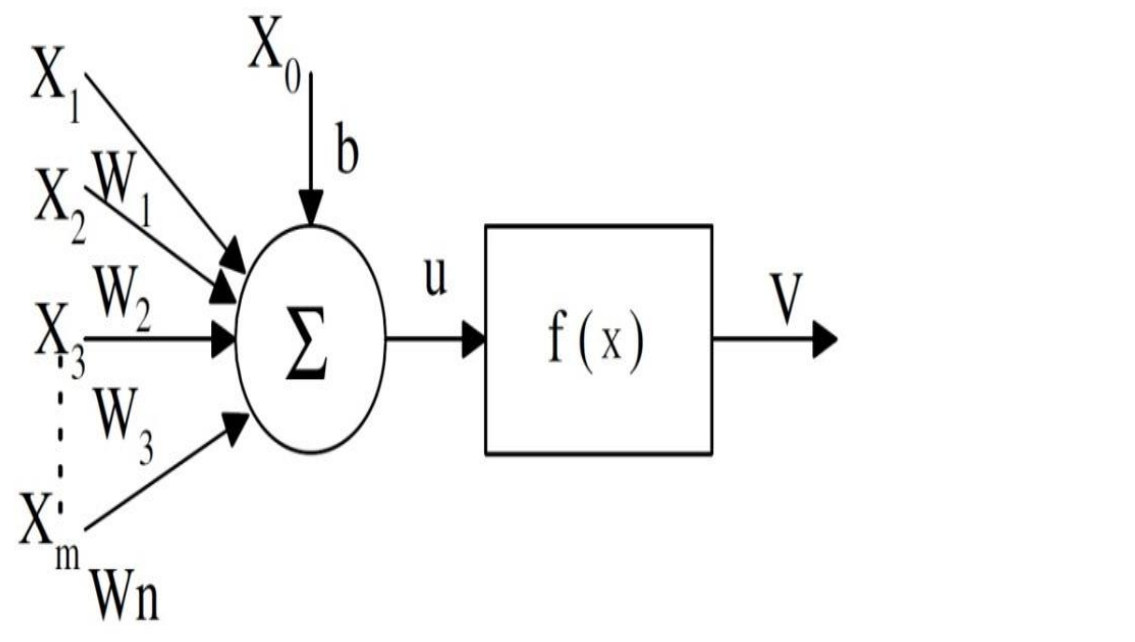

Figure 5. Artificial Neuron Model

Let $\mathrm{X}=\left(\mathrm{X}_{1}, \mathrm{X}_{2} \ldots \mathrm{X}_{\mathrm{m}}\right)$ represent the $\mathrm{f}$ input applied to the neuron. Where $\mathrm{W}_{\mathrm{n}}$ represents the weight for input $X_{m}$ and $b$ is a bias, then the output of the neuron is given. These neurons are connected with connection link. Each link has a weight that is multiplied by transmitted signal in network. Each neuron has an activation function to determine the output. There are many kinds of activation functions. Usually nonlinear activation functions such as sigmoid, step are used. ANNs are rained by experience, when an unknown input is applied to the network it can generalize from past experiences and produce a new result [8-10].

Artificial neural networks are systems that are deliberately constructed to make use of some organizational principles resembling those of the human brain [8-10]. They represent the promising new generation of information processing systems.

When designing an ANN model, a number of considerations must be taken into account. At first the suitable structure of the ANN model must be chosen. Then, the activation function need to be determined. The number of layers and the number of units in each layer must be chosen. Generally desired model consists of a number of layers. The most general model assumes complete interconnections between all units. These connections can be bidirectional or unidirectional. ANN can create its own organization or representation of the information it receives during learning time [8-10]. There are many kind of ANN structure. 


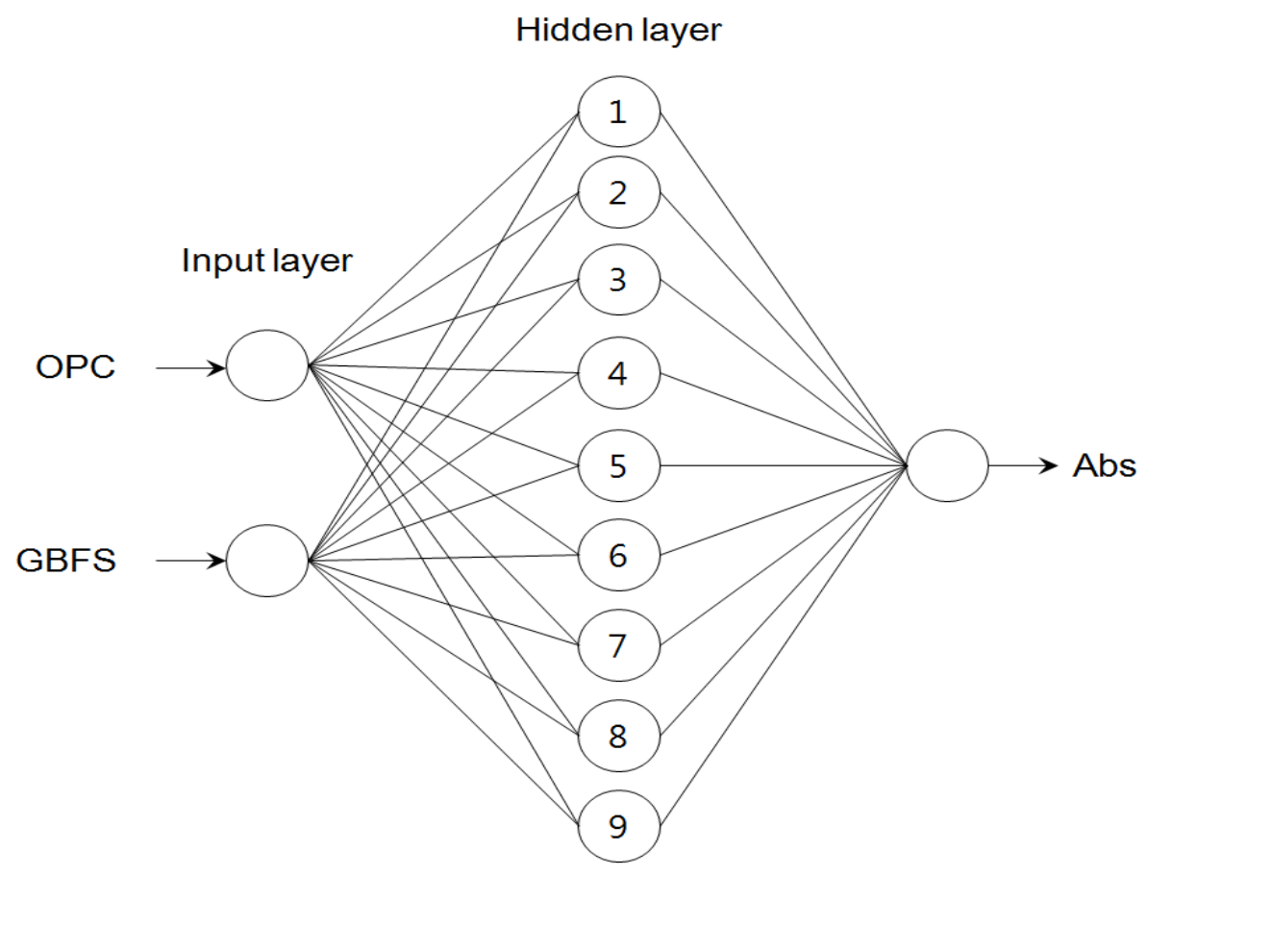

Figure 6. Artificial Neural Network Architecture

In this study, the problem is propesed to network models by means of two inputs and one output parameter. The parameters such as amount of OPC, amount of GBFS and age of samples were selected as input variables. The model output variable was the concentration ammonia of the mortar. A data set including 72 data samples obtained from experimental studies were used for artificial neural networks. The data were normalized by dividing with max values. The back propagation learning algorithm has been used in a feed-forward, single hidden layer neura network. ANN architecture used for this study is given in Figure 6.

In the design of neural network, it is very important to determine an appropriate number of hidden layer codes. Exactly, there is an empirical formula which is used to calculate this number:

$$
H=\sqrt{m+n}+\mathrm{a}
$$

$\mathrm{m}$ is the number of input layer

$\mathrm{n}$ is the number of output layer

a is a number which arranges from 1 to 10

Through a lot of experiences, number 9 is the best which can achieve our accuracy requivement.

The some algorithms of ANN were used for this study but the Levenberg-Marquardt (LM) algorithm, One Step Secant backpropagation algorithm (OSS) and BFGS quasi-Newton back propagation algorithm were just learning. The computer program was performed under MATLAB software using the neural network toolbox. In the training, the number of neuron on the hidden layer is nine. A data set including 72 data samples obtained from experimental studies were used for artificial neural networks. 
International Journal of Smart Home Vol.8, No.2 (2014)
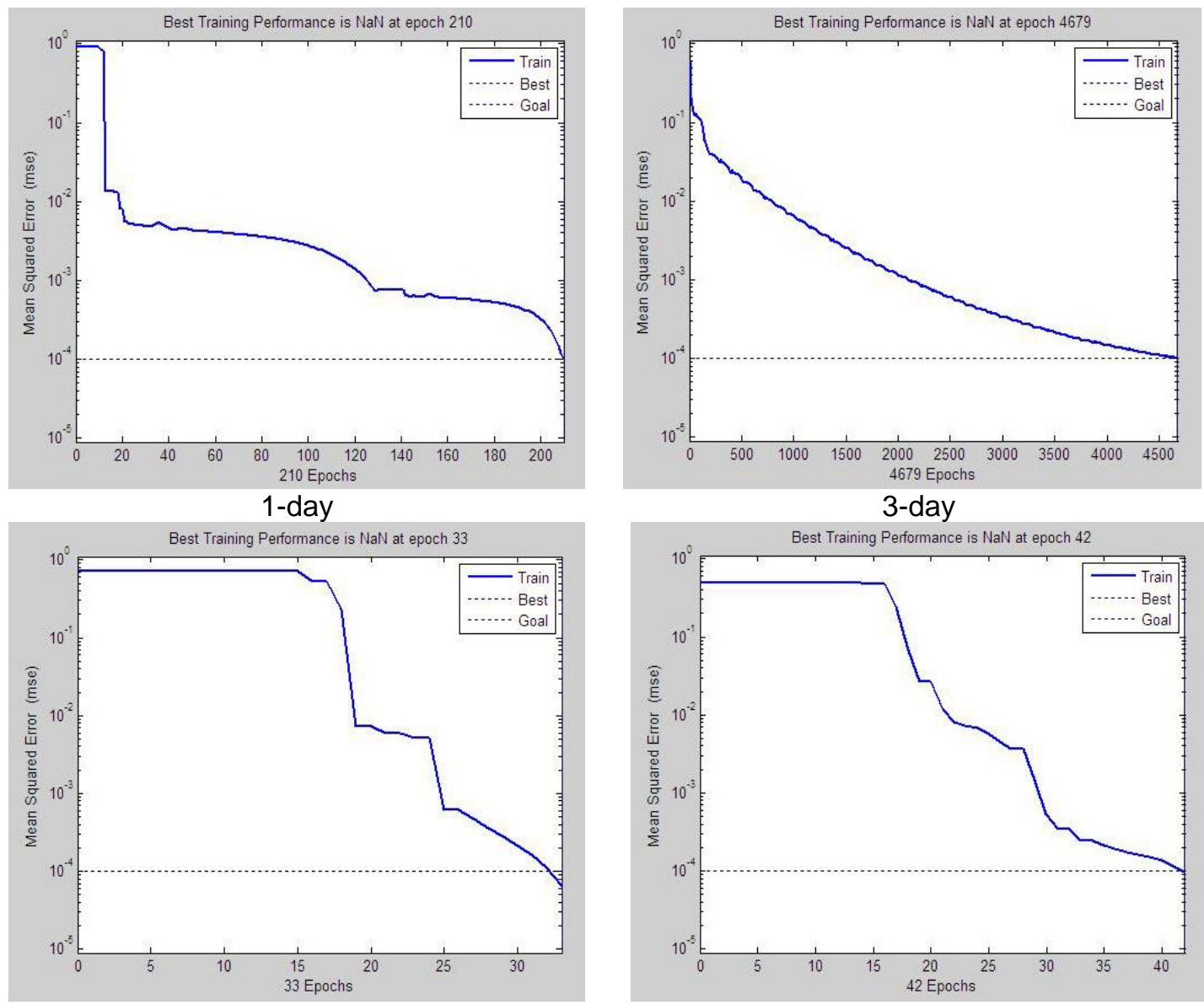

3-day
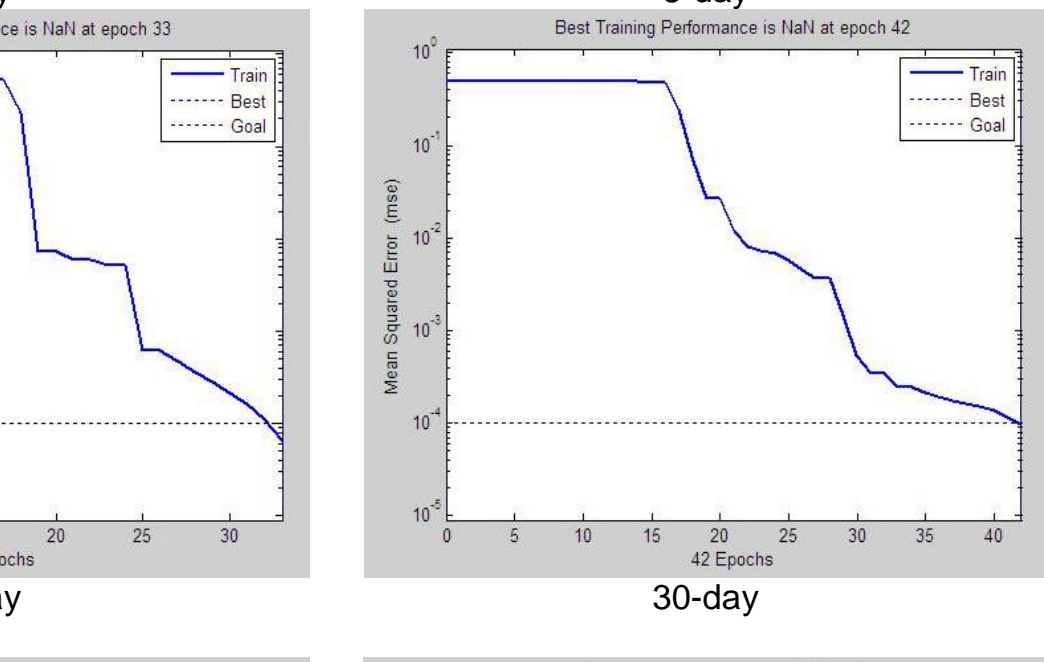

30-day
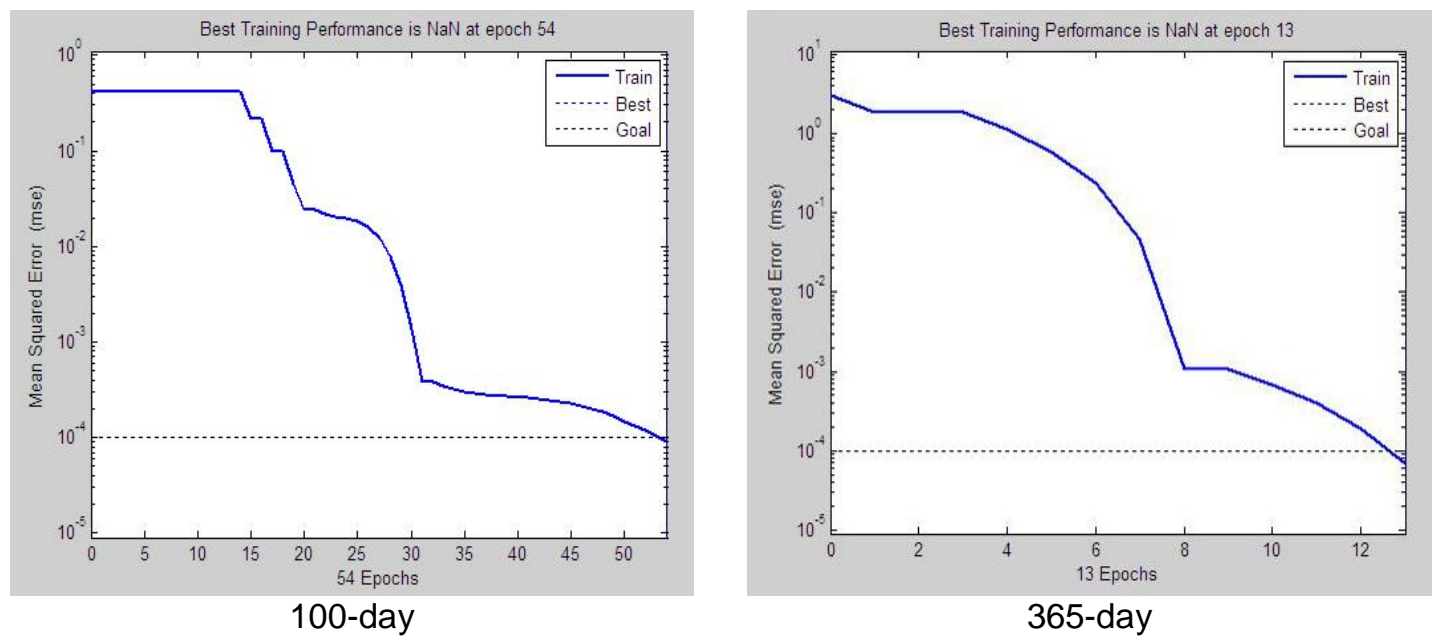

Figure 7. One Step Secant Backpropagation Algorithm 

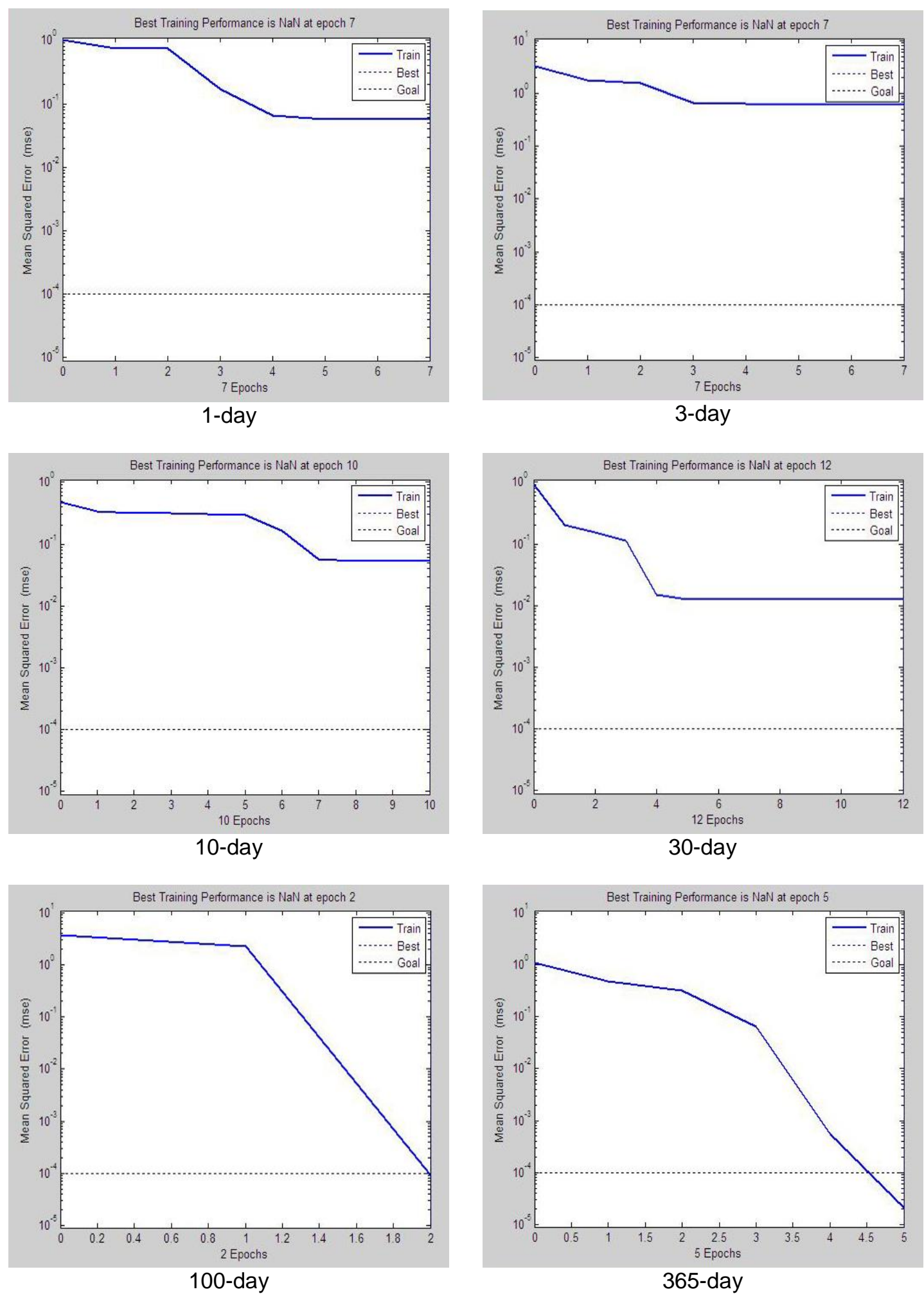

Figure 8. BFGS Quasi-Newton Backpropagation Algorithm 

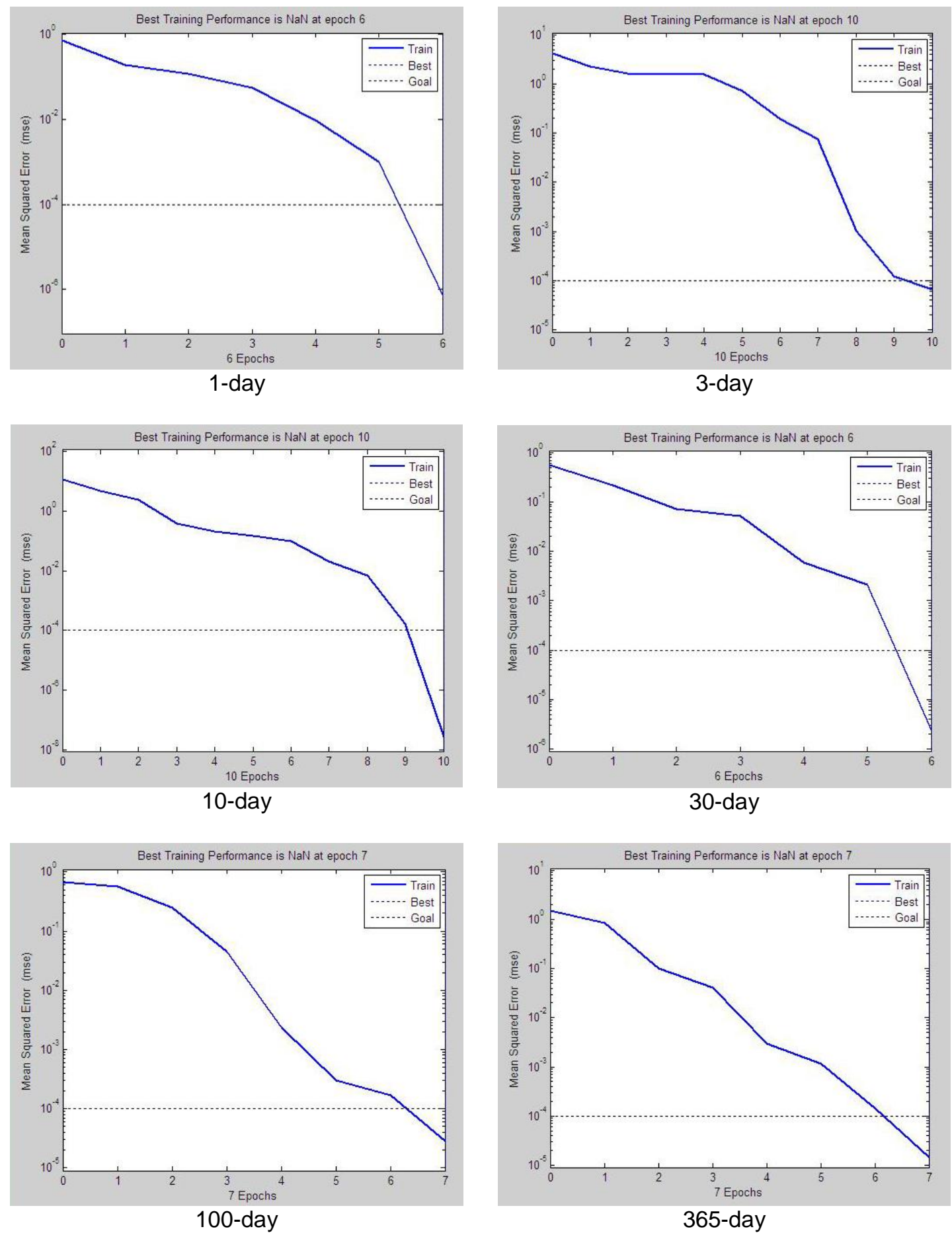

30-day

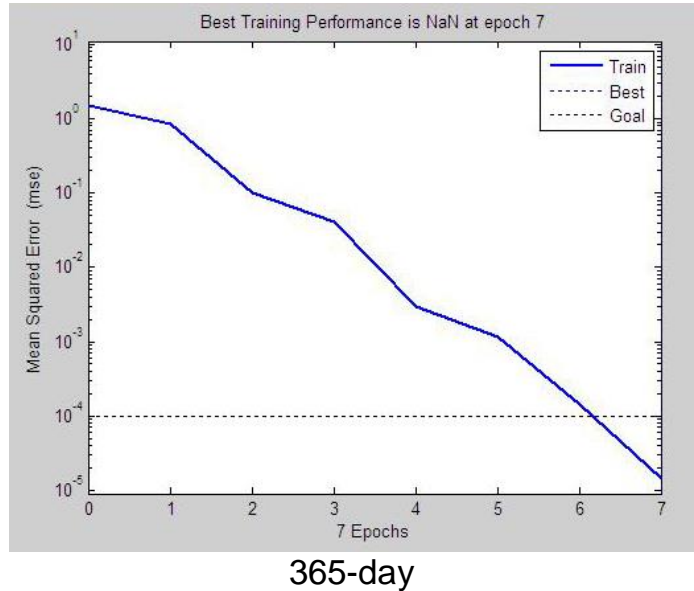

Figure 9. Levenberg-Marquardt Algorithm

The training performance during the training process is given in Figures 7-9 where the variation of mean-square error with training epochs is illustrated. It can be seen from these figures that Levenberg-Marquardt algorithm is the best learning algorithm for study. 


\section{Conclusion}

1) GBFS replacement by weight increases the emission of ammonia in early age when compared to control OPC mortar. However, in long term, mortar containing GBFS exhibits an equivalent or little more than that of control OPC mortar.

2) The ANN model predicts the emission of ammonia of mortar containing GBFS with the high correlation coefficient. Therefore, the results show that the ANN can be used to predict the emission of ammonia of GBFS mortar.

\section{Acknowledgement}

This article is a revised and expanded version of a paper entitled [Predicting the ammonia concentration of cement mortar using artificial neural network] presented at Intemational Symposium on Advanced and Applied Convergence held on November 14-16, 2013 at Seoul, Korea.

This work was supported by the National Research Foundation of Korea Grant Funded by the Korean Government (NRF-2007-0055805).

\section{Reference}

[1] B. Liang, "Indoor air pollution-ammonia pollution", Proceeding of international workshop on indoor air quality, State environmental protection administration of China, Beijing, China, (2001) August 86-90.

[2] A. B. Spencer and M. G. Gressel, "Hazard and -perability study of anhydrous ammonia application in agriculture", American Industrial Hygiene Association journal, vol. 54, no. 11, (1993), pp. 671-677.

[3] The Engineering ToolBox. Ammonia-N/3-concentration, in air and health symptoms, http://www.Engineeringtoolbox.com/ammønia-bealth-symptoms-d_901.html.

[4] U.S. Department of Health and Human Services. Occupational safety and health guideline for ammonia, (1992) September 1-7.

[5] C. E. Amshel, M. H. Fealk, B. I Phillips and D. M. Oaruso, "Anhydrous ammonia burns case report and review of the literature", Burns, vol. 26, (2000) pp. 493-497.

[6] U.S. Public Health service, Agency for toxic substances and disease registry (ASTDR) toxicological profile for ammonia, (1990) December 1-57.

[7] H. S. Jang, M. R. Lề and S. Y. So, "Predicting the ammonia concentration of cement mortar using artificial neural network", 1 st internationa symposium, International Symposium on Advanced and Applied Convergence, Se6ul, Korea, (2013) Noyember, pp. 183-185.

[8] Hanbay D Turkoglu I. and Demir Y. An expert system based on wavelet decomposition and neural network for modeling chya's circuit. Expent systems with applications, vol. 34, no. 4, (2008), pp. 2278-2283.

[9] S. Haykin, "Neural networks, a comprehensive foundation", 1st. Prentice Hall PTR Upper Saddle River, NJ, USA, (1994).

[10] D. Hanbay, I. Turkog $U$ and Y. Demir, "Prediction of wastewater treatment plant performance based on wavelet packet decomposition and neural networks", Expert systems with applications, vol. 34, no. 2, (2008), pp. 1038-1043.

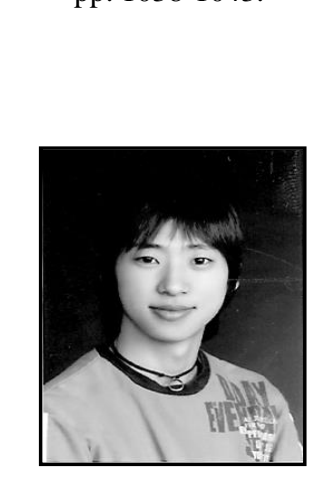

\section{Authors}

Hongseok Jang, is a researcher in the Department of Architectural Engineering at Chonbuk National University, South Korea. He received his $\mathrm{PhD}$ from Chonbuk National University, South Korea. His research interests include the hydration gas in concrete. 


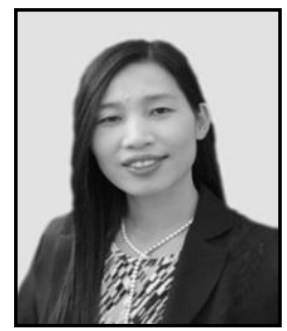

Malrey Lee, is an associate Professor in the Department of Electronics and information Engineering and member of Research Center for Advanced Image and Information Technology at Chonbuk National University, South Korea. She has over forty publications in various areas of Computer Science, concentrating on Artificial Intelligence, Robotics, Medical Healthcare and Software Engineering.

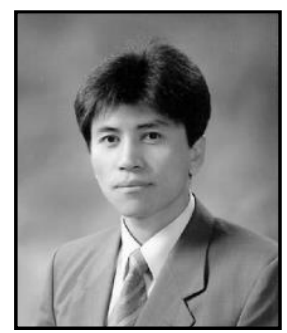

Seungyoung So, is an associate Professor in the Department of Architectural Engineering and Head of Research Center of Industrial Technology at Chonbuk National University, South Korea. His research interests include the hydration gas of concete and development of clean concrete.

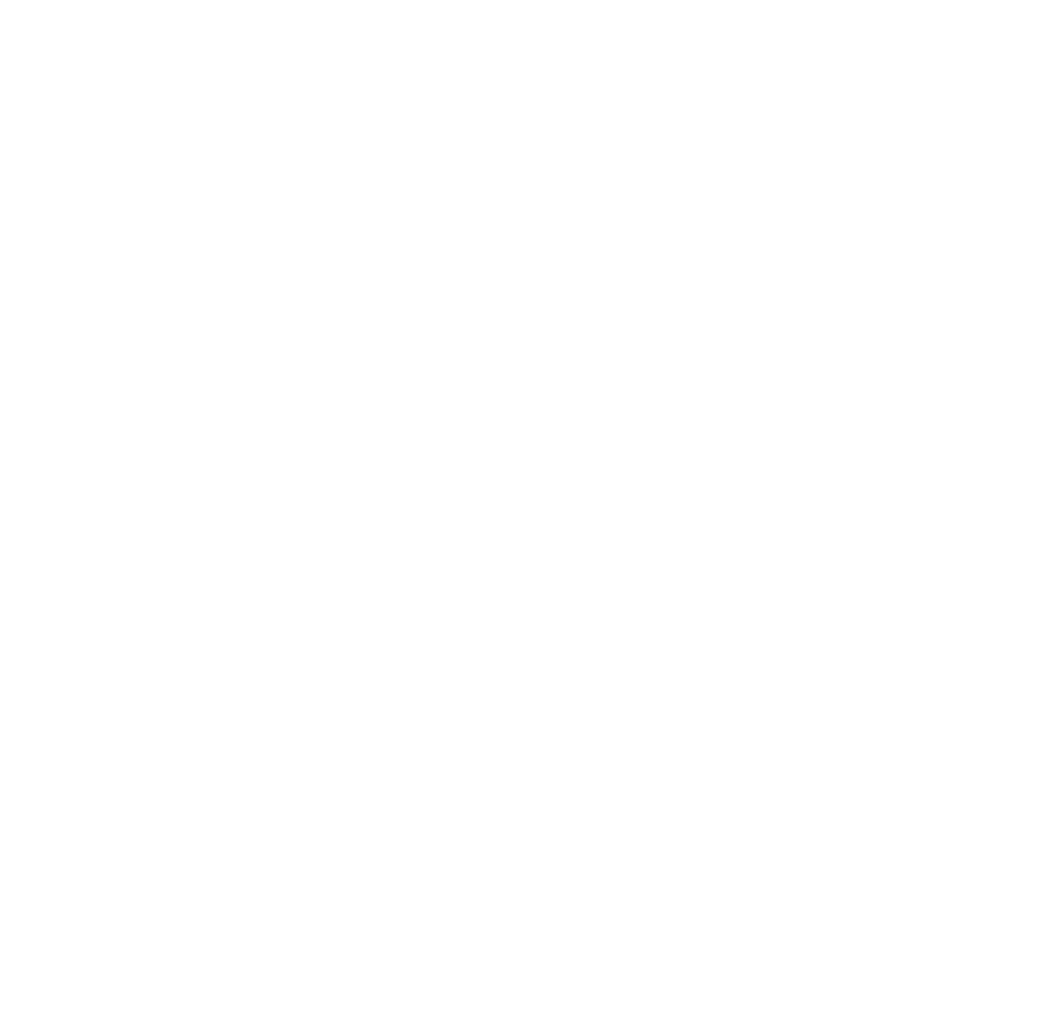

